\title{
Prospective elementary teachers' abilities in tackling a contextualized physics problem as guided inquiry
}

\author{
Antonio García-Carmona*10 \\ ${ }^{1}$ Universidad de Sevilla, Departamento de Didáctica de las Ciencias Experimentales y Sociales, España.
}

Received on October 9, 2019. Accepted on October 21, 2019.

\begin{abstract}
This article presents a qualitative study, with a descriptive and interpretative nature, of the abilities of prospective elementary teachers (PETs) to solve a contextualized problem of physics through a process of guided inquiry. Specifically, an analysis was made of the PETs' abilities to (a) formulate hypotheses; (b) plan inquiry procedures aimed at testing hypotheses; and (c) draw conclusions from the inquiry (i.e., interpret experimental data to accept or reject their hypotheses, and recognize the limitations of the inquiry that they had conducted). The study participants were 17 PETs who were receiving training in science teaching. They were organized into small groups to solve the physics problem proposed to them. The study's data were extracted from the inquiry reports that the groups prepared by following a script with open-ended questions. The results revealed the PETs' strengths and weaknesses in addressing the different scientific practices that had been required in the process, as well as showing that they all had achieved some improvement in their inquiry abilities after completing the activity. A discussion of the results is given with a view to improving the training of PETs in inquiry-based science learning.
\end{abstract}

Keywords: inquiry abilities, elementary teacher training, science education, scientific inquiry, thermal phenomenon.

\section{Introduction}

Inquiry is considered as one of the most suitable strategies for learning science $[1,2]$, especially if the students are to learn science by doing science [3]. While there is no an univocal conception of inquiry-based science learning (IBSL) [4], it could be said in general that IBSL is an approach in which students [5]: $(i)$ develop key scientific ideas progressively by learning how to investigate and build their own knowledge to understand the (physical) world around them, and ( $i i)$ themselves use the abilities that scientists use, such as asking questions, gathering data, reasoning about and reviewing evidence from what is already known, drawing conclusions, and discussing results.

Nevertheless, at the basic educational levels, the traditional teaching approaches, which have little to do with IBSL, still predominate in science classes [6]. Likewise, the supposed scientific inquiries that are normally set in class are reduced to nothing more than simply observing a phenomenon by manipulating some instruments and materials, uncritically following cook-book style closed instructions step by step [7]. The result is that the students usually focus almost entirely on completing those instructions instead of learning about and understanding what they are doing [3]. Apart from this, the students are often asked to carry out scientific inquiries without having the scientific knowledge and abilities necessary

${ }^{*}$ Correspondence email address: garcia-carmona@us.es to do so $[8,9]$. Likewise, it is common for students to have difficulty in interpreting the data deriving from an experiment [10], and in general in relating what is observed in an inquiry with scientific knowledge [11].

At the base of this problem are science teachers themselves. They are generally insufficiently prepared and/or with lack confidence to promote an IBSL approach in their classes [12]. This is particularly significant in the case of elementary science teachers [13]. Prospective elementary teachers (PETs) always begin their training with conceptions on how to teach science which have been built mainly from the science classes they themselves received during their schooling [14]. In most cases, this experience was based on traditional educational approaches [15], and thus generates internal conflicts in the PETs that often hinder their assimilation of alternative pedagogical approaches such as those which are inquiry based [12].

The deficient scientific knowledge and abilities with which PETs generally access their training in science education also represent a major obstacle to them acquiring the teaching abilities they will need to be able to teach science through inquiry [16]. Therefore, it seems reasonable that the training of PETs in teaching science through an IBSL approach begins by their first experimenting with simple scientific inquiries as if they themselves were science students [17]. This can help the PETs to recognize this approach as being suitable resources to integrate theory with scientific practice; and above all they also 
can gain confidence in how to design and develop activities based on IBSL [18]. The purpose of this study is therefore to present a qualitative study on the abilities of PETs to solve a contextualized problem of physics through guided inquiry.

\section{Inquiry-based science education}

There is a certain consensus regarding the features that characterize the construct of scientific inquiry. According to Lederman et al. [19], it can be said that: $(i)$ all scientific inquiries start with a question or problem, but this does not have necessarily to be oriented to testing a hypothesis (an example is the case of exploratory studies); (ii) there is no single, universal, algorithmic method that is followed in all inquiries (i.e., there is no single "scientific method"); ( iii) the processes of scientific inquiry are themselves guided by the question that was posed; (iv) different researchers, following the same procedures, may get different results; $(v)$ the inquiry processes used may influence the results; (vi) the conclusions of the inquiry must be consistent with the data collected; (vii) scientific data and scientific evidence are different things; and (viii) the interpretations in an inquiry come from a combination of the data collected and what was already known in the science of the phenomenon in question.

On the other hand, the scientific hypotheses are conceived of as tentative solutions or responses to some scientific problems [20], whose veracity can be tested through experiments. Therefore, the scientific problems have to be asked as researchable inquiry questions [21]. This requires applying knowledge about variables (i.e., parameters that vary from those that are controlled in an experiment), and about how to design methods to collect data in order to find significant patterns and consequently to test whether or not data are consistent with an initial hypothesis [22]. In this sense, the formulation of hypotheses should be underpinned in systematic and organized knowledge bearing in mind the current state of that knowledge [23]. Guisasola, Ceberio and Zubimendi [24] distinguish three types of hypotheses, depending on the nature of the scientific inquiry: (i) descriptive hypotheses, which affirm something that has not yet been confirmed, and are related to factual knowledge (events, phenomena, facts, etc.); (ii) explanatory hypotheses, which speculate on the causes of phenomena (relationships between two or more variables), and whose predictions are based on deductive reasoning; and (iii) procedural hypotheses, which refer to knowledge of how to carry out experiments, measurements, and other procedural practices.

In transposing all the above tasks and perspectives of scientific inquiry to the reality of science classes, some authors [25, 26] suggest, among other aspects: $(i)$ posing questions that are challenging, but still approachable, for the students (i.e., that are recognizable within the students' usual context, and researchable in school), and that demand reasoning, explanation, and reflection, in which the students put their ideas into play and subject them to analysis; ( $i i$ ) helping the students in the use and development of abilities for collecting data and interpreting evidence; ( $i i i$ ) fostering access to a diversity of procedures and ideas through the discussion and management of different sources of information; $(i v)$ recognizing the students' achievements during the experimentation, and encouraging them to continue until they get to the end of the inquiry; $(v)$ ensuring that the students keep a record of their observations during the inquiry, which will facilitate their subsequent interpretation and discussion of the results; ( $v i$ ) encouraging the students to discuss the procedures they used, the results obtained, etc., in both small groups and the class as a whole; and (vii) allocating time for the students to reflect on what they have learnt.

In setting up school-level scientific inquiries, the teacher should take into account the students' characteristics and their familiarity with the ISBL approach [18], the scientific content involved [17], and the learning objectives that are hoped to be attained [3]. In addition, it is necessary to determine what degree of openness the inquiry put to the students should have. In this regard, MartinHansen [27] distinguishes four types of inquiry: (a) Open inquiry, which begins with a students' inquiry question, followed by the students designing and conducting an investigation or experiment and communicating results; (b) Guided inquiry, in which teacher asks the question for investigation and helps students develop the inquiry; (c) Coupled inquiry, which combines guided-inquiry with open-inquiry (e.g., the teacher askes the inquiry question and students autonomously develop the inquiry activity); and (d) Structured inquiry, which is completely guided by the teacher and it typically results in a cook-book activity.

Furthermore, according to Kirschner, Sweller and Clark [28], scientific inquiry is usually more effective educationally when it is more guided, even with students accustomed to the IBSL approach. This is because students always need some kind of support when they learn science through inquiry [29]. Thus, even when guided scientific inquiries are proposed in which the students should propose their own procedures to carry out, it is normally useful for the teacher to design a script to guide them [30], while leaving enough room for them to be challenged in the execution of each of the phases of the inquiry. Likewise, it is suggested that these scripts should include questions to encourage the students' metacognitive reflection, in order to make them aware of their achievements and the difficulties they faced [18], and, in general, to develop critical thinking in the context of a scientific inquiry [31].

\section{Aims of the study}

In accordance with the above, the purpose of this article is to describe a qualitative, descriptive, and interpretative study which analyzed the as that PETs showed when they 
resolved, for the first time, a contextualized physics problem via inquiry. Taking into account the different tasks or processes usually required to fully develop a scientific inquiry [26], the research question underpinning the present study was the following: What abilities do PETs have to (a) formulate hypotheses given a problem about a physical phenomenon; (b) plan inquiry procedures aimed at testing hypotheses; and (c) draw conclusions from the inquiry (i.e., interpret experimental data in accepting or rejecting hypotheses, and recognize the limitations of the inquiry they had done)?

\section{Methods}

\subsection{Participants and context}

The participants in the study were 17 PETs (13 women and 4 men), from 20 to 37 years in age (mean age, 22.5 years). The participants formed a subgroup-class of the subject Science Teaching (90 teaching hours) which the author of the present study taught. The PETs selected for this study therefore constituted by those to whom the researcher had access at the time of the study; i.e., a convenience sample.

The subject Science Teaching corresponds to the 2nd year of the Undergraduate Degree in Elementary Education of a Spanish university. Its purpose is for the PETs to: $(i)$ reflect on and understand the purpose of basic science education; $(i i)$ analyze the elementary education school science curriculum; ( $i i i)$ know what conceptions and difficulties students usually have when they are learning science; $(i v)$ become familiar with the resources and strategies for science teaching and evaluation; and $(v)$ learn to design plans and activities for teaching science in elementary education. For these last two objectives, inquiry is especially promoted as an ideal educational approach to learning science by doing science.

Regarding the profile of the participants, most of them had had unsatisfactory experiences with science during their own lower (compulsory) secondary education stage (12-16 years). Therefore, almost all had opted for academic itineraries not related to science in their upper (post-compulsory) secondary education (16-18 years). Indeed, students of the Undergraduate Degree in Elementary Education (i.e., PETs) generally have a low preference for science and for teaching it. They also have very limited scientific knowledge, and their experience or familiarity with the IBSL approach is very sparse [15]. This is partly due to the fact that in Spanish elementary school classes there still predominates a traditional form of teaching science that encourages superficial rote learning of the content [6].

During the first year of their Degree course, the PETs receive instruction about basic science fundamentals (150 teaching hours in total). This includes content of chemistry, geology, and biology. Physics content is not included, however, so that, when the PETs begin the subject Sci- ence Teaching, they have major lacunae in their knowledge related to school Physics. Also, their instructors in the basic foundations are not specialists in science education, and usually take a traditional educational approach based on the transmission of already prepared knowledge. In addition, the laboratory activities proposed in these classes are of the cook-book type, which the PETs carry out uncritically and mechanically, following the instructions of a closed script step by step. In sum, the participants in the present study came to the Science Teaching course with no prior experience of inquiry-based approaches.

\subsection{School science content selected for the scientific inquiry}

In accordance with the approaches taken by Newman et al. [17] and the academic characteristics of the PETs, an important challenge in the Science Teaching course was to improve the PETs' knowledge of the scientific content together with their pedagogical knowledge of that content. Consequently, for this study, a topic of physics content was chosen that: $(i)$ was academically novel for the participants in that they needed to learn about it because they had not addressed it before, or had done so only in a very shallow way; $(i i)$ was included explicitly in the science learning standards for elementary education (6-12 years old); (iii) referred to some physical phenomenon easily recognizable by elementary students in their daily lives; and ( $i v$ ) favored the development of school-level scientific inquiry accessible to students at basic levels.

The content finally selected was related to heat because students have everyday experiences with thermal phenomena from when they were very young; although their understanding about it is usually inadequate [32]. Park and Song [33] have recently verified that solving problems about thermal phenomena in elementary education favors the students' cooperative learning and the gradual transformation of their intuitive thinking into logical thinking.

The basic understanding of thermal phenomena is an explicit part of the science learning standards for elementary education in Spain [34]. In the block entitled "Matter and Energy", the following learning standards are set out (the parts directly related to thermal phenomena are in italics) (p. 20):

- Observe, identify, describe, and classify some materials by their properties (hardness, solubility, state of aggregation, thermal conductivity);

- Plan and perform simple experiments and predict changes in movement, form, or state of the bodies due to the effect of forces or inputs of energy, communicating the process followed and the result obtained; 
- Identify and explain some of the main characteristics of the different forms of energy: mechanical, light, sound, electrical, thermal, chemical; and

- Observe systematically, appreciate, and explain the effects of heat on the increase in temperature and expansion of some materials.

\subsection{Description of the activity and data collection}

It was decided to propose a guided scientific inquiry related to an everyday thermal phenomenon for the PETs to carry out. I.e., from a question or problem of high order (i.e., relating variables) for scientific inquiry put forward by the instructor, the PETs had to formulate a hypothesis based on a tentative response to the problem. Then they had to explain the strategies followed to check the validity of their hypothesis, i.e., planning the experiment, data collection procedure(s), etc. Next, they had to draw conclusions from their inquiry, including their interpretation of the data they had obtained, with the help of scientific literature, to determine in a well-founded manner whether their hypothesis was valid. Finally, they had to make a critical assessment of the possible errors or limitations of their inquiry process. Figure 1 shows the script they were provided to guide them through these aspects.

For the inquiry process, the PETs were organized into groups of 2 or 3 members (seven groups in total: G1 to G7). This was done in order to promote a working climate in class based on permanent interaction and discussion, which favors cooperative and collaborative learning. It was assumed that the interaction between individuals faced with a common task usually produces more clearly elaborated answers or opinions since it encourages discussion and the search for consensus to combine the different points of view of the group members [35]. In this sense, it was followed the Sohr's, Gupta and Elby [36] recommendations for group work, and the instructor aided all the groups to properly manage the cases of agreement or disagreement that arose during their discussions. Likewise, when a group requested help or some clarification during the development of the inquiry, the instructor provided the necessary support for them to be able to progress, although always leaving sufficient margin for challenges that they would need to face.

The inquiry was carried out in three class sessions of $1.5 \mathrm{~h}$ each. In the first session, the inquiry was presented to the groups in accordance with the script shown in Figure 1. In the second session, the groups did the experiments they had planned in order to test their hypotheses. All the groups had the same materials available for their experiments (i.e., plastic, stainless steel, glass, or ceramic cups, test tube, thermometer, and water) and a refrigerator to cool and/or freeze water. Finally, the third session was devoted to the groups sharing their results and conclusions.

All the data collected as required for the tasks in the inquiry script were registered by each group in a group report, which they submitted two weeks after the last session. The content of these reports was subjected to

\section{THE PROBLEM FOR INQUIRY}

Some friends get together to organize a birthday party. It's summer, and they plan to have a refreshing drink, but they're not sure what type of glass or cup to use to make the drink stay cool longer while they are drinking it. They discuss whether to use plastic, stainless steel, ceramic, or glass, but no one is convinced about which would be the best option. If you were one of them, what would your proposal be and why?

\section{SCRIPT FOR PLANNING AND DEVELOPING THE INQUIRY}

1. Establish a hypothesis. Try to advance a possible solution or response to the question, attempting to base it on the scientific knowledge you have about the phenomenon.

\section{Strategy to test the hypothesis.}

2.1 Plan the experiment: Think about and explain what procedure you are going to follow to check the validity of your hypothesis.

2.2 Observe the phenomenon and record data: Explain what data you will take and how you will process it.

3. Conclusion drawn from the inquiry.

3.1 Scientific interpretation of the results: Explain whether the results obtained are coherent with what science establishes respecting the phenomenon analyzed.

3.2 Verify the hypothesis: In view of the results obtained and their scientific interpretation, determine whether or not your hypothesis is valid.

3.3 Detect the limitations of the inquiry: Indicate what errors, limitations, or difficulties (conceptual and/or procedural) you think you had during the inquiry.

Figure 1: Script for the scientific inquiry. 
a qualitative analysis along the lines of other similar research [18, 30, 37].

\subsection{Data analysis}

The content of the groups' reports was analyzed from a descriptive and interpretative perspective [38]. Given the open nature of the tasks proposed in the inquiry script, a wide ranging, diverse body of information was obtained. Consequently, the information was analyzed by the instructor in three phases to progressively refine the coding of this [39], and therefore to achieve a categorization as representative as possible of the abilities and difficulties of the PETs in tackling a school scientific inquiry. In order to contribute to the objectivity of the study, the Shenton's [40] suggestions of being careful that the data and interpretations are minimally biased by the researcher's expectative were followed. For that, throughout the whole process of categorization, the researcher was based on the theoretical framework exposed above. Likewise, the data were collected systematically, including with the use of low inference descriptors [41] consisting of excerpts of the groups' textual responses to the different questions.

Following the Mayring's [42] method for qualitative content analysis, in the first phase a preliminary categorization was established inductively according to the patterns or tendencies observed in the groups' responses to the different tasks in the inquiry script. After approximately two months, the second phase of the analysis was performed in which the content of the reports was revised again, with some modifications being introduced into the initial categorization. These modifications affected approximately $25 \%$ of the responses and they consisted basically in the creation of new categories, the regrouping of others, and the decomposition of some into various subcategories. For example, in the case of the hypotheses that the groups had formulated, the initial categorization classified them into adequate, partially adequate, or inadequate. However, the need to go more deeply into the PETs' capacities and difficulties in this regard led to a more sophisticated categorization of the hypotheses. In particular, a distinction was made between hypotheses based on experiential knowledge and those based on scientific knowledge. This latter category was then further broken down into three subcategories according to whether the scientific knowledge was adequate, partially adequate, or inadequate. Finally, about a month later, the third phase was performed in which the content of the reports was revised once again to make some further fine-tuning until arriving at the final categorization (it affected approximately $10 \%$ of the responses). It is necessary to clarify that, in tune with what Bengtsson [43] notes regarding the categorization processes, this final categorization was assumed as definitive because the researcher considered that the categories and subcategories established already allowed him to respond reasonably to the aims of the study. In this final phase it was also decided how to represent in tables the different values or elements for the categories related to the groups' hypothesis testing strategies and the interpretation of experimental data.

\section{Results}

\subsection{Abilities in formulating hypotheses}

The problem put to the PETs requested the formulation of an explanatory hypothesis. It has to be clarified, however, that the groups were not expected to correctly explain which of the four materials (ceramic, glass, plastic, or stainless steel) is the best thermal insulator (or has the lowest thermal conductivity) because, among other reasons, it would be difficult to know this with precision unless one had extensive knowledge in materials science. Ceramic, glass, and plastic have relatively similar thermal conductivities in comparison with stainless steel, so that it is easy to discard the latter as a good thermal insulator. But deciding between plastic, ceramic, and glass as the best thermal insulator is not so simple. Therefore, what was expected with the formulation of a hypothesis was that the groups would at least try to justify scientifically their choice of material, with a view to subjecting it to experimental verification. In this sense, any hypothesis was considered adequate that based the choice of material on an approximate scientific explanation in terms of the material's structure and composition, the mobility of the electrons inside it, etc.

The results are presented in Table 1. Only group G4 formulated a hypothesis based entirely on scientific knowledge. Their hypothesis, nonetheless, reflected that this knowledge was quite inadequate for the phenomenon being studied. Thus, they showed they had a partially adequate conception in considering that "the thermal insulation of a material depends on its thickness", but inadequate in that "the materials conduct temperature" or that "the materials retain the heat". The following is an excerpt from their hypothesis:

G4: "[...] The stainless-steel cup would not be valid because, being metal, it is a good conductor of temperature and would retain the heat. On the other hand, glass and ceramic, being thicker materials, will isolate the water more [from the exterior]."

Groups G1, G2, and G6 proposed hypotheses that were not based on scientific knowledge, but on everyday or experiential knowledge. Example:

G2: "We think that a good solution would be ceramic because, for example, in the old days when there were no refrigerators, water was kept in ceramic pots because it remained fresh for a longer time. This would be because this material is a good thermal insulator." 
Table 1: Hypotheses formulated by the groups.

\begin{tabular}{|c|c|c|c|}
\hline \multirow{3}{*}{$\begin{array}{l}\text { Types of hypothesis } \\
\text { Hypothesis based on everyday or } \\
\text { experiential knowledge }\end{array}$} & & Explanatory basis used & \multirow{2}{*}{$\begin{array}{l}\text { No. of groups } * \\
\text { G1, G3, G5, G6, G7 }\end{array}$} \\
\hline & & $\begin{array}{l}\text { Personal experience with the } \\
\text { materials }\end{array}$ & \\
\hline & & Traditional use of materials & G2, G3, G7 \\
\hline \multirow{7}{*}{$\begin{array}{l}\text { Hypothesis based } \\
\text { knowledge }\end{array}$} & Adequate scientific knowledge & & - \\
\hline & $\begin{array}{l}\text { Partially adequate scientific knowl- } \\
\text { edge }\end{array}$ & $\begin{array}{l}\text { Thicker materials are better } \\
\text { thermal insulators }\end{array}$ & G4 \\
\hline & Inadequate scientific knowledge & $\begin{array}{l}\text { Materials absorb both heat and } \\
\text { cold }\end{array}$ & G7 \\
\hline & & $\begin{array}{l}\text { Materials are temperature con- } \\
\text { ductors }\end{array}$ & G4 \\
\hline & & Insulating materials retain heat & G4 \\
\hline & & $\begin{array}{l}\text { More compact materials are bet- } \\
\text { ter thermal insulators }\end{array}$ & G3 \\
\hline & & $\begin{array}{l}\text { Less porous materials are better } \\
\text { thermal insulators }\end{array}$ & G5 \\
\hline
\end{tabular}

* Some groups included more than one explanatory base in their hypotheses. When they combined scientific and experiential justifications in the hypotheses, these were denoted as mixed.

The rest of the groups (G3, G5, and G7) set out hypotheses that could be classified as mixed in the sense that they were based on both scientific and experiential knowledge. The following is an example of these hypotheses:

G3: "To keep drinks cold for longer, the best option would be to use ceramic since it is a compact and insulating material for both cold and heat [...]. We have several reasons to choose this, for example our own experience in using it. In addition, in the past, our ancestors used this material [...] for food and drink to maintain their temperature for longer."

The above hypothesis shows that the members of the group consider that the thermal insulation of a material is related to its compactness. Other conceptions that were detected in the mixed hypotheses were that the thermal conductivity of the materials depends on their porosity, or that the materials "absorb" both cold and heat:

G5: "[...] we think that stainless steel is more insulating and less porous, therefore the best to keep the drink cold."

G7: "We think that glass is a conductor, although we are not sure, what we do know is that it absorbs both cold and heat and we usually put glasses in the freezer [at home] so that the drink stays cold longer. We know that stainless steel is a super conductor, this would imply a great amount of absorption of the cold from the drink that would be lost quickly, because of this, in Thermos flasks there is a second insulating layer of another material behind the stainless steel."

\subsection{Abilities in setting up hypothesis testing procedures}

Table 2 presents a synthesis of the results of the analysis of this aspect. In the groups' proposals, three different experimental procedures were found, denominated Procedures A, B, and C. Procedure A consisted in measuring the change over time of the water temperature in each type of cup without a lid. Procedure B was the same as Procedure A, but the PETs surrounded the cup with their hands (see Figure 2). Procedure C consisted in measuring the time it took for a piece of ice to melt in each type of cup (Figure 3). Procedure A was the one that most of the groups followed (4 of the 7 groups). Procedure C was only used by group G4. Two groups used more than one procedure: group $\mathrm{G} 1$ used procedures $\mathrm{A}$ and $\mathrm{B}$, and group G4 procedures B and C. In their report, group G2 explained how they used procedure A as follows:

G2: "[...] we took the four cups of the different materials [...] Then we took the water from the refrigerator, we measured its temperature

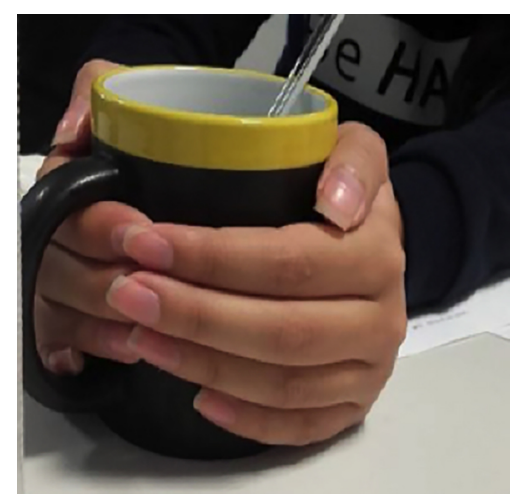

Figure 2: Illustration of experimental procedure B. 


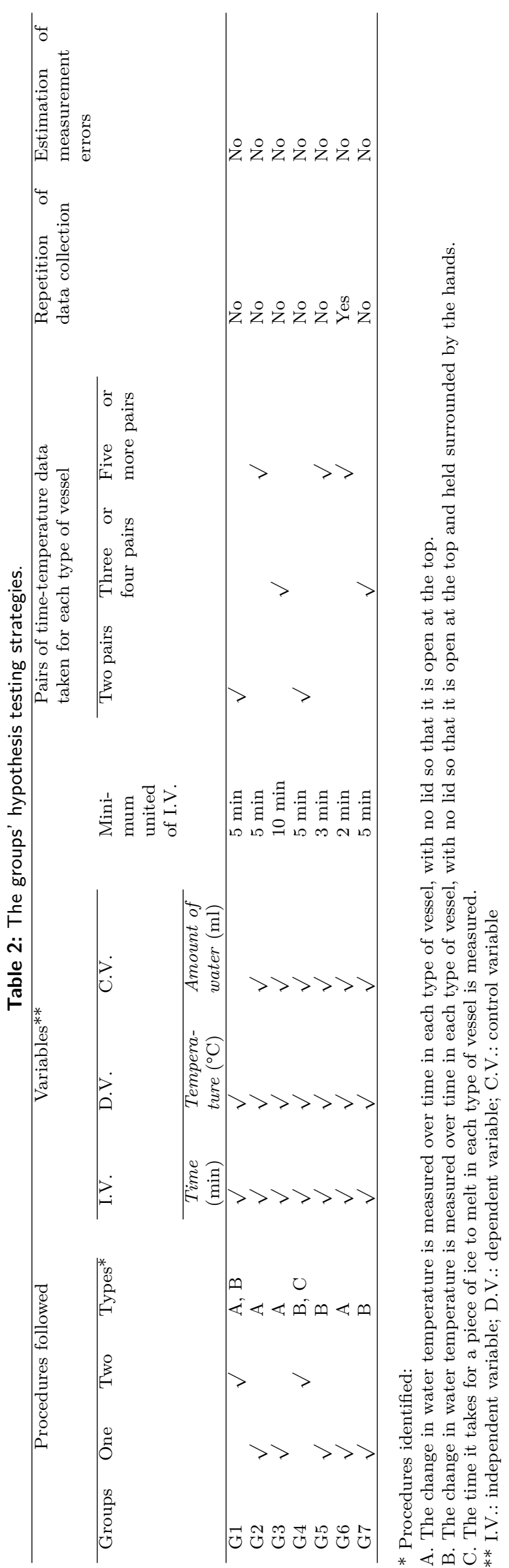

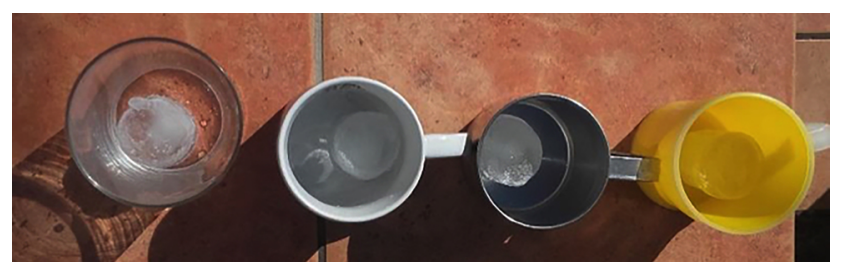

Figure 3: Illustration of the experimental procedure $\mathrm{C}$.

$\left(10^{\circ} \mathrm{C}\right)$ with a thermometer and we poured $40 \mathrm{ml}$ into each cup; to do this we used a plastic test tube. We could have poured more [water into each cup], but we did not know if we would have enough [cold water]. First, we thought to take a thermometer for each container, but we only had one, so we measured the temperature of the water in each vessel every five minutes, and we made a table [with the data obtained] [...]."

Procedure B was described by group G7 as follows:

G7: "We used cold water and [...] we had two thermometers, so we measured [the temperature changes in the vessels] two by two. [...] We held the cup in our hands. This was a last-minute decision, since we did not plan it, but we thought that doing this we would get closer to the reality of the situation and also save time as the interchange would occur faster. We used a fixed measure of 100 $\mathrm{ml}$ for all the cups, that we measured with a test tube. After filling the first two cups, we put the bottle with the cold water back into the fridge to try to keep the initial temperature of these two cups the same for the following three [cases], or at least as close as possible. Previously, we measured the ambient temperature $\left(20^{\circ} \mathrm{C}\right)$. We measured the initial temperature of the water once it was put into the cup, and, holding the vessel in a hand (changing hands every 10 minutes), we took measurements every 5 minutes to a maximum of 15 minutes."

Regarding procedure C, group G4 used it in the following way:

G4: "To verify the hypothesis, we used [...] different strategies and/or ways of checking the experiment. [...] Procedure 2: We placed the four cups in the sun, at an ambient temperature of about $25^{\circ} \mathrm{C}$, and directly we put an ice cube, of equal size, into each of the cups. The reason for putting them in the sun was for the process to be carried out in a faster way. [...] We left the vessels in the sun for 30 minutes. Once that time had elapsed, 
the amount of water, which had changed from a solid to liquid state of each of the ice cubes, was poured into another [...] vessel, which we used as a reference to calculate which cup had melted the most ice [in that time]."

In addition to the experimental procedures used by the groups, especial attention was paid to how they managed the variables and their interest in obtaining accurate and reliable data. As shown in Table 2, practically all the groups chose appropriate variables, establishing time as an independent variable, water temperature as a dependent variable, and the amount of water poured into the vessels as a control variable (with the exception of group G1 which did not control it). However, we did find that the minimum unit of the variable time varied considerably from one group to another. Thus, while group G6 established a minimum time of 2 minutes, group G3 set it at 10 minutes, with which its first measurement was nearly at the situation of thermal equilibrium of each vessel with the surrounding medium, making it hard to observe any noticeable differences in thermal insulation between the different vessels. There also stood out the small amount of data that the groups took. This was especially so for groups G1 and G4 who only took two pairs of data - the initial time and water temperature $\left(\mathrm{t}_{0}=0\right.$ and $\left.\mathrm{T}_{0}\right)$, and the final values ( $\mathrm{t}$ and $\left.\mathrm{T}\right)$. Only three groups (G2, G5, and G6) took five or more pairs of data.

Finally, it was striking that only group G6 decided to repeat their measurements in order to obtain more reliable data. Likewise, no group paid attention to possible measurement errors due to lack of precision of the measurement instruments, the limited abilities of the group members in taking measurements, etc.

\subsection{Abilities in interpreting experimental data and recognizing limitations of an inquiry}

Table 3 summarizes the results of this final part of the inquiry. First, it should be noted that all the groups except G1 interpreted their results with the help of information consulted in the scientific literature. This was essential for the groups to be able to assess the degree of validity of their hypotheses.
Only three of the seven groups (G1, G4, and G7) concluded that their hypotheses had been confirmed after the experiment. However, what was really important for this educational experience was that the groups were able to give scientific reasons for accepting or rejecting their hypotheses. For example, group G2 stated in their hypothesis that the ceramic vessel would be the best thermal insulator, but in their experimental tests they found that the order of the vessels according to insulating capacity was: $1^{\text {st }}$ plastic, $2^{\text {nd }}$ glass, $3^{\text {rd }}$ ceramic, and $4^{\text {th }}$ stainless steel. Then, after searching for information, they concluded that their results were fairly concordant with those provided by the scientific literature regarding the specific heats of these materials. This is how they expressed it:

G2: "Our initial hypothesis is not confirmed since we thought that ceramic would be the material that would best conserve the temperature, and according to the results we obtained the best thermal insulator is plastic. [...] According to the information [consulted] about the different specific heats of these materials, we can say that we came up with quite successful results. First, the [cup of] plastic would be that [which has the] highest specific heat, i.e., it takes a lot of energy to increase its temperature $\left[1^{\circ} \mathrm{C}\right]$, coinciding with our results. The [cup of] steel is the one that has the lowest specific heat. [The cups of] ceramic and glass have values [of specific heat] closer to each other, of about $800 \mathrm{~J} / \mathrm{kg} \bullet \mathrm{K}$."

Another example of how the groups presented their conclusions based on the results obtained and their consultation of scientific literature is the following:

G6: "We were finally able to conclude that our hypothesis formulated at the beginning is not valid. Our results were totally contrary, i.e., the material that is best suited to keeping the beverage cold, according to our experiment, is plastic, and the worst, stainless steel. [This we can explain] thanks to the concept of specific heat [...]. Stainless steel has a specific value

Table 3: Interpretation of data with which to test the hypotheses, recognition of the limitations of the inquiry, and improvements in understanding the phenomenon.

\begin{tabular}{|c|c|c|c|c|c|}
\hline \multirow[b]{2}{*}{ Groups } & \multirow[t]{2}{*}{$\begin{array}{l}\text { Data interpreted on the basis } \\
\text { of the scientific literature }\end{array}$} & \multirow[t]{2}{*}{$\begin{array}{l}\text { Confirmation of } \\
\text { the hypothesis }\end{array}$} & \multicolumn{2}{|c|}{$\begin{array}{l}\text { Awareness of the } \\
\text { inquiry's limitations }\end{array}$} & \multirow[t]{2}{*}{$\begin{array}{l}\text { Persistence of inade- } \\
\text { quate conceptions }\end{array}$} \\
\hline & & & $\begin{array}{l}\text { Concep- } \\
\text { tual }\end{array}$ & Procedural & \\
\hline G1 & & $\sqrt{ }$ & $\sqrt{ }$ & $\sqrt{ }$ & No \\
\hline G2 & $\sqrt{ }$ & & & & No \\
\hline G3 & $\sqrt{ }$ & & $\sqrt{ }$ & & Yes \\
\hline G4 & $\sqrt{ }$ & $\sqrt{ }$ & & $\sqrt{ }$ & Yes \\
\hline G5 & $\sqrt{ }$ & & $\sqrt{ }$ & & Yes \\
\hline G6 & $\sqrt{ }$ & & $\sqrt{ }$ & & No \\
\hline G7 & $\sqrt{ }$ & $\sqrt{ }$ & & $\sqrt{ }$ & Yes \\
\hline
\end{tabular}


of $510 \mathrm{~J} / \mathrm{kg} \cdot \mathrm{K}$, and ceramic a specific heat of $840 \mathrm{~J} / \mathrm{kg} \cdot \mathrm{K}$ approximately. This means that stainless steel will need less heat for the temperature to increase, so in this material the temperature of the water increases faster than in ceramic, which needs more energy to increase [the temperature of] the mass of water by one degree."

Attention was also paid to whether the groups were aware of the limitations of their inquiry. Four groups made some reference to conceptual limitations. For example, after the experiment and consultation of the scientific literature, group G5 stated that their hypothesis had not been adequately substantiated:

G5: "[...] we had several failures when elaborating the hypothesis. We were not basing ourselves on scientific sources, but on our own experience. [...] At first, we thought that the [vessel] that would best maintain the temperature would be the stainless steel one; we thought about how it is a conductor, but we did not realize that while it cools fast it will also warm up just as quickly. That was our biggest mistake. We thought [also] of such elements as porosity, but in this case, it did not influence anything."

Group G3 became aware of how problematic it is to leave a significantly long time between one measurement and another, because the water reaches thermal equilibrium with the surrounding medium in a relatively short period of time. This was explained in their report:

G3: "[...] we noticed that during the first five minutes the water temperature in the four vessels gradually increased. [...] also, that three of the vessels reached the same temperature after 20 minutes. This makes us think that, after a certain time, the water temperature inside any type of vessel, whatever the material, will increase until it remains constant. [...] when two bodies that have different temperatures come into thermal contact, after a certain time, they reach the equilibrium condition where both bodies are at the same temperature. This balance occurs because the body that is at higher temperature (in this case the vessel) transfers heat to the body that is at lower temperature (water) until both are equal."

With respect to procedural limitations, just 3 out of the 7 groups indicated one or more in their conclusions. For example, group G1 tried to express in a generic form that, despite confirming their hypothesis experimentally, they had not been meticulous enough in the procedure followed and the data collection: "[...] our initial hypothesis has been confirmed with the experiment [...]. However, because of not having made a truly accurate verification, we could not fully verify our hypothesis since the method used and the data are somewhat imprecise." (G1)

After contrasting their results with the scientific literature, group G7 concluded that they should have controlled the thickness of the vessel walls in their experiment so that they were all the same so to avoid any influence of this factor on the thermal insulation. This was explained as follows: "[...] we have seen that the thickness [of the walls of the vessels] is important when clarifying the results. Vessels with fixed and equal thicknesses would be necessary [...]." (G7)

Finally, the conclusions phase of the inquiry also served to determine which improvements the PETs had experienced in their understanding of the phenomenon they had studied. In general, it can be said that all the groups showed improvements in their knowledge about the thermal phenomenon analyzed. At the beginning of the inquiry (in their formulation of hypotheses), none of the groups expounded adequate ideas about the thermal conductivity of materials. It was noteworthy, therefore, that three of the seven groups (G1, G2, and G6) showed themselves to have acquired a quite adequate understanding of the phenomenon after the inquiry (as evidenced by some of the textual citations given above). In the other four groups (G3, G4, G5, and G7), despite the improvements in the understanding they had acquired, some inadequate scientific concepts continued to be detected, for example, confusing heat with temperature, as group G5 expressed in its conclusion: "The phenomenon observed here is clearly conduction. To understand this, we have to think of heat as agitation, i.e., the movement and collision of particles [of material] [...]." Or that materials can conduct both heat and cold:

G4: "We can conclude that we have obtained this result since plastic is a good temperature insulator, i.e., it does not conduct cold or heat, so the drink will take longer to warm up [...]. Therefore, the plastic cup will be the optimal material to keep the drink cold."

\section{Discussion}

The present results reveal that, in general, the participating PETs showed themselves to have weakly developed abilities for carrying out a scientific inquiry about a contextualized physics problem. This was to be expected considering the limited academic (scientific and didactic) background with which they had begun their initial science education training. However, the purpose of the study was not only to determine whether or not the PETs had difficulties in conducting a scientific inquiry. The intention was rather to analyze in detail how they faced the different tasks required in the complete execution of a scientific inquiry in order to gain some insight into their 
potentialities and their difficulties in doing this type of activity.

\subsection{Abilities in formulating hypotheses}

The first inquiry task that the PETs faced was to formulate a hypothesis as a response or tentative scientific solution to the problem posed. Given the nature of that problem, it was not expected that the PETs would formulate correct hypotheses, but that at least they would try to justify their initial choice of the best thermal insulating material based on the scientific knowledge they possessed about the phenomenon. The purpose was for them then to check for themselves the veracity of their hypotheses by means of a guided inquiry.

As in studies with secondary school students [8], undergraduate students [22] and prospective secondary education science teachers [42], it was found that all the participating PETs had difficulties in formulating adequate explanatory hypotheses about the question set them for inquiry. However, a novel aspect of the present study was that the analysis of the hypotheses did not focus only on determining hierarchically whether these were more or less correct scientifically. Rather, it was analyzed whether or not the hypotheses that were formulated could be categorized as scientific, regardless of their level of scientific correctness. This led to the hypotheses being distinguished between those based on scientific knowledge and those based on experiential or everyday knowledge. The results indicated that practically all the groups formulated hypotheses totally or partially based on everyday knowledge. This revealed, firstly, that, as with secondary students [11], the PETs showed themselves to have difficulties in explaining everyday phenomena on the basis of scientific knowledge. Secondly, the fact that the PETs based the justifications of their hypotheses on experiential knowledge indicated that they had weakly informed knowledge concerning the nature and role of scientific hypotheses. Therefore, the inquiry activity that was proposed to them allowed a diagnosis to be made of, on the one hand, their conceptions of the thermal phenomenon being analyzed (e.g., "materials are conductors of temperature", or "materials absorb both heat and cold"), and, on the other, their understanding of the nature of hypotheses in the context of a school-level scientific inquiry.

\subsection{Abilities in setting up hypothesis testing procedures}

The PETs proposed experimental procedures that were of three types, with some groups using more than one type in their experiments. These results suggest, firstly, that leaving the learners some freedom to plan their own procedures, while being able to count on the appropriate scaffolding provided by the instructor and with the help of a guiding script [30], can contribute to their development of creative and divergent thinking in a context of inquiry- based learning. Secondly, guided scientific inquiries such as that carried out by the participating PETs may favor in them the idea that there is no single method or procedure for carrying out a scientific inquiry.

In their experiments, practically all the groups made an adequate identification of the independent, dependent, and control variables. This contrasts with the difficulties found in studies of prospective secondary education science teachers [9]. It is possible that the problem put forward for inquiry in the present study was less complex than the problems addressed in those other studies. Nevertheless, what stands out from the present study is that a simple inquiry such as that proposed here can favor the identification of variables in students who are still unfamiliar with this scientific practice.

The results were less satisfactory with respect to the rigor and precision in the data collection. The PETs showed little awareness of the need to choose appropriately the values of the independent variable (in this case, "time") in order to observe changes in the dependent variable ("temperature") that would favor a coherent interpretation of or response to the problem they had been proposed. Indeed, the fact that some groups chose relatively long-time intervals made it difficult for them to observe how the different materials evolved thermally before reaching thermal equilibrium with the surrounding medium. Furthermore, no group made any reference to possible errors in their measurements. This is common among PETs unless they are explicitly asked for this in the development of an inquiry [18]. Similarly, by far most of the groups took very little data and did not see any need to repeat their measurements. Consequently, the study showed that the PETs had limited abilities for the measurement of physical magnitudes. This finding suggests that this scientific practice should be given particular attention in the formation of PETs in the IBSL approach since the measurement of magnitudes is a basic objective of scientific-mathematical education from the elementary levels onwards.

\subsection{Abilities in interpreting experimental data and recognizing limitations of an inquiry}

Regarding the interpretation of experimental data, it is worth highlighting the effectiveness of proposing the PETs the specific task of consulting sources of scientific information as support for this inquiry practice. Almost all the groups made adequate use of this support from the scientific literature in order to determine the veracity or validity of their hypotheses. Likewise, this task favored all the PETs' achievement of an improvement (some more than others) in their, initially low, level of understanding of the physical phenomenon they were analyzing. Therefore, the process the PETs had followed was conducive to their arriving at that final stage of looking up information in a mental and reflective state in which they were more open to understanding the scien- 
tific knowledge involved in the inquiry. In short, as in the study of Park and Song [33] with elementary students, the proposed inquiry helped the PETs to move from an intuitive form of thinking to a more scientific one.

This was reinforced by the task of metacognition proposed at the end of the inquiry for the PETs to reflect on the difficulties and limitations that they had encountered. Most of the groups stated that they were aware of conceptual errors in their formulation of a hypothesis (e.g., justifying the hypothesis on the basis of inadequate scientific knowledge), or in their experimental design (e.g., not having established the appropriate intervals for the values of the variable "time" given that objects tend towards thermal equilibrium with the surrounding medium). Also, although in a lesser proportion, the groups were aware of their procedural limitations (e.g., limitations in data collection). Consequently, it can be said that making this task part of the inquiry not only favored the PETs' conceptual and procedural learning, but also encouraged their critical thinking [18, 31].

\section{Conclusions, implications and limitations of the study}

The studies on the abilities of learners in general, and of PETs in particular, with the IBSL approach usually offer a rather pessimistic outlook. This basically is because the approach is far from straightforward to implement in class. The difficulties involved are even greater when the teacher has a limited science background, as is the case of PETs. Nonetheless, the international science education community continues to see scientific inquiry as being one of the best strategies for learning science by doing science. Therefore, even bearing these difficulties in mind, it is worth continuing to look deeper into how to improve PETs' scientific and teaching abilities so as to promote IBSL in elementary education science classes. The qualitative analysis of scientific inquiries such as the one presented here may be a good way to approach this. In this study, descriptive and interpretative in profile, the PETs' inquiry abilities were analyzed in the context of a complete scientific inquiry initiated by a high-order scientific question (i.e., relating variables). This allowed us to do a global and integrated evaluation of the PETs' abilities and difficulties to conduct the tasks which are required in this type of scientific inquiry. Thus, there was an attempt from the beginning to find what are PETs' weaknesses and strengths in carrying out a school scientific inquiry. Indeed, although the PETs began the inquiry with major difficulties in deciding how to approach and execute the proposal properly, various of their abilities clearly improved (although not all of them to a desirable level) as they completed the proposal. The main weaknesses found were the following: (a) difficulties in formulating adequate explanatory hypotheses and misunderstanding of the nature of them; (b) difficulties in choosing appropriately the values of the independent vari- able; (c) disregards for errors in the measurements and lack of awareness of need to repeat measurements in an experiment; and (d) difficulties in interpreting the data deriving from an experiment without external assistance.

And the strengths were the following: (a) an adequate identification of the different variables in the experiment; (b) abilities to check the validity of hypotheses in the inquiry from a support in scientific literature; (c) awareness of the difficulties and limitations encountered during the inquiry; (d) improvement of both the understanding of content and inquiry abilities thanks to the critical and reflective approach whereby the inquiry was raised; and (e) transition from an intuitive knowledge, which was predominant at the beginning of inquiry scientific, to a more scientific one at the final of this. These strengths -still with room for improvements- constitute without doubt good reasons for optimism because it reveals the potentialities of the inquiry activity planned for the PETs training in IBSL approach. Although, the identification of the weaknesses is also an important finding to continue improving. They will orientate us to determine in which specific inquiry tasks or practices we should pay more attention in future training plans in IBSL approach. Even this study has already revealed how some of these weaknesses can be addressed; for example, the consulting of scientific literature helps the PETs to scientifically interpret their empirical data. In addition, we think that other weaknesses such as that related to become aware of need to repeat measurements in order to improve the validity of an experiment, or to choose appropriately the values (in scale and quantity) of the independent variable, could be relatively easy to address in future instructions with PETs.

However, we think that other weaknesses such as that referred to formulate adequate explanatory hypotheses are more complex to address. First, this requires the PETs improve their scientific knowledge, which demands to integrate it in the training plans in IBSL, and this is not an easy issue as some studies have shown [17]. Even so, as has just been said, this study has pointed out some clue regarding how to undertake this; for instance, to make explicit the need of consulting scientific content when the empirical data have to be interpreted in order to test the initial hypothesis. Second, it demands the PETs improve their understanding of the nature of scientific hypotheses; namely, tentative explanations of natural phenomena that have to be testable scientifically. In this study only a small portion of PETs were aware of this at the final of the activity. Therefore, in future training plans a special effort will be made for the PETs understand the scientific hypotheses cannot be based on everyday knowledge, and their plausibility must be checked against scientific knowledge.

On the other hand, it is necessary to mention the limitations of the present study. One such would be the fact that the inquiry was circumscribed to a specific topic of the school science curriculum. I.e., the question remains 
as to whether the PETs' strengths and weaknesses regarding their abilities for inquiry would have been observed if the topic had been taken from some other content of the science curriculum. In this sense, it would be interesting to analyze and compare what occurs when PETs are asked to carry out scientific inquiries about different topics in the elementary education science curriculum. However, the present study has provided results that transcend the science topic chosen (results that would be cross-cutting) and could be extrapolated to the development of school-level inquiries about other content. Examples are the utility of providing the PETs with a script to guide them in carrying out the inquiry, the effectiveness of including a task that involved consulting sources of information as part of their process of interpreting their data to accept or reject their hypothesis, and the importance of encouraging them to make a final metacognitive reflection on the possible limitations of the inquiry they had planned and carried out.

Another possible limitation of the study is that the PETs prepared their reports as groups. One has to wonder whether the responses in the reports really represented the opinions of all a group's components, or whether those of the component with the greatest dialectical capacity or conviction imposed themselves on the others. To mitigate this to the fullest, the instructor's extensive experience in promoting reflective discussions among PETs in small groups during a scientific inquiry was essential. As was noted above in Methods, during the inquiry the instructor encouraged all the groups, with insistence and providing them with the appropriate scaffolding, to make sure that their responses arose from discussion and consensus among all of each group's components. Even so, in future studies it would be interesting for each component, together with the group report, to prepare an individual report which, in addition to reflecting their own responses, would invite them to reflect on their participation in and contribution to the development of the group's responses and decisions in carrying out the inquiry.

Finally, it has to be noted as a limitation of the study that the participants were a small sample chosen for convenience. This means that the conclusions are limited and not generalizable to the population of PETs in Spain, let alone in other countries. However, in accordance with Elliott [44], the detailed description of the context of the study, together with the actions adopted to ensure its validity and reliability, mean that its results can be taken to be an important source for reflection and orientation in the development of other studies in similar contexts and circumstances.

\section{Acknowledgements}

This study was supported by the Ministry of Economy, Industry and Competitiveness (Government of Spain) under grant EDU2017-82505-P.

\section{References}

[1] F. Abd-El-Khalick, S. Boujaoude, R. Duschl, N.G. Lederman, R. Mamlok-Naaman, A. Hofstein, M. Niaz, D. Treagust and H.L. Tuan, Sci. Educ 88, 397 (2004).

[2] M. Rocard, P. Csermely, D. Jorde, D. Lenzen, H. Walberg and V. Hemmo, Science education now: A renewed pedagogy for the future of Europe (European Commission, Brussels, 2007).

[3] D. Hodson, Int. J. Sci. Educ. 36, 2534 (2014).

[4] D.D. Minner, A.J. Levy and J. Century, J. Res. Sci. Teach. 47, 474 (2010).

[5] Inter-Academy Partnership, Taking inquiry-based science education into secondary education. A global conference (IAP Science Education Program, York, 2010).

[6] P. Cañal, A.M. Criado, A. García-Carmona and G. Muñoz-Franco, Invest. Esc. 81, 21 (2013).

[7] A. García-Carmona, A.M. Criado and M. CruzGuzmán, Int. J. Sci. Math. Educ. 16, 237 (2018).

[8] C. Ferrés, A. Marbà and N. Sanmartí, Rev. Eureka Enseñ. Divulg. Cienc. 12, 22 (2015).

[9] B. Aydoğdu, Asia Pac. Forum Sci. Learn. Teach. 16, 1 (2015)

[10] Z. Kanari and R. Millar, J. Res. Sci. Teach. 41, 748 (2004).

[11] I. Abrahams and R. Millar, Int. J. Sci. Educ. 30, 1945 (2008).

[12] B.A. Crawford, J. Res. Sci. Teach. 44, 613 (2007).

[13] S. Gatt and C. Zammit, in: International trends in preparation of early childhood teachers in a changing world, edited by J. Bałachowicz, K. Nowak-Fabrykowski and Z. Zbróg (Wydawnictwo Akademii Pedagogiki Specjalnej, Warszawa, 2017).

[14] T. Russell and A.K. Martin, in: Handbook of Research on Science Education, Volume II, edited by S.K. Abell and N.G. Lederman (Routledge, New York, 2014).

[15] A. García-Carmona, M. Cruz-Guzmán and A.M. Criado, Invest. Esc. 84, 31 (2014)

[16] H.G. Yoon, Y.J. Joung and M. Kim, Res. Sci. Educ. 42, 589 (2012).

[17] W.J. Newman, S.K. Abell, P.D. Hubbard, J. McDonald, J. Otaala and M. Martini, J. Sci. Teach. Educ. 15, 257 (2004)

[18] A. García-Carmona, Int. J. Sci. Math. Educ. 17, 1 (2019).

[19] J.S. Lederman, N.G. Lederman, S.A. Bartos, S.L. Bartels, A.A. Meyer and R.S. Schwartz, J. Res. Sci. Teach. 51, 65 (2014).

[20] M. Wenham, Int. J. Sci. Educ. 15, 231 (1993).

[21] M. Cruz-Guzmán, A. García-Carmona and A.M. Criado, Int. J. Sci. Educ. 39, 1755 (2017).

[22] National Research Council, A framework for K-12 science education: Practices, crosscutting concepts, and core ideas (The National Academies Press, Washington, 2012).

[23] D. Denis, Rev. Cub. Cien. Biol. 2, 1 (2013).

[24] J. Guisasola, M. Ceberio and J.L. Zubimendi, Res. Sci. Educ. 36, 163 (2006).

[25] P. Cañal, A. García-Carmona and M. Cruz-Guzmán, Didáctica de las Ciencias Experimentales en Educación Primaria (Paraninfo, Madrid, 2016).

[26] W. Harlen, Inq. Prim. Sci. Educ. 1, 5 (2014).

[27] L. Martin-Hansen, Sci. Teach. 69, 34 (2002). 
[28] P.A. Kirschner, J. Sweller and R.E. Clark, Educ. Psychol. 41, 75 (2006)

[29] J.C. Arnold, K. Kremer and J. Mayer, Int. J. Sci. Educ. 36, 2719 (2014).

[30] A. García-Carmona, A.M. Criado and M. Cruz-Guzmán, Res. Sci. Educ. 47, 989 (2017).

[31] K.D. Seraphin, J. Philippoff, L. Kaupp and L.M. Vallin, Sci Educ Int 23, 366 (2012).

[32] R. Driver, E. Guesne and A. Tiberghien, Children's ideas in science (Open University Press, Philadelphia, 1985).

[33] J. Park and J. Song, J. Res Sci Educ, 1 (2018)

[34] Education Ministry, Royal Decree 126/2014, February 28, establishing the basic curriculum of elementary education (6-12 years old) (Official Bulletin of the State, Madrid, 2014).

[35] L. Salmerón, Rev. Educ. 34 (2013).

[36] E.R. Sohr, A. Gupta and A. Elby, Sci. Educ. 102, 883 (2018).

[37] V. Nivalainen, M.A. Asikainen and P.E. Hirvonen, Phys. Rev. ST Phys. Educ. Res. 9, 010102 (2013).

[38] R. Elliott and L. Timulak, in: A handbook of research methods for clinical and health psychology (Oxford University Press, New York, 2005).

[39] E. Blair, J. Meth. Meas. Soc. Sci. 6, 14 (2015).

[40] A.K. Shenton, Educ. Inf. 22, 63 (2004).

[41] C. Seale, The quality of qualitative research. Introducing qualitative methods series (SAGE, London, 1999).

[42] P. Mayring, Forum Qual. Soc. Res. 1, 1 (2000).

[43] M. Bengtsson, Nurs. Plus Open 2, 8 (2016).

[44] J. Elliott, La investigación-acción en educación (Morata, Madrid, 2000). 